\title{
Trend Analysis on Maternal Health Care Services Utilization in Amhara Region Referral Hospitals, Ethiopia
}

\author{
Genanew Timerga ${ }^{1,}$, , Solomon Hailemeskel ${ }^{2}$ \\ ${ }^{1}$ College of Natural and Computational Science, Department of Statistics, Debre Berhan University, Debre Berhan, Ethiopia \\ ${ }^{2}$ College of Health Science, Department of Midwifery, Debre Berhan University, Debre Berhan, Ethiopia
}

Email address:

genanewtim@gmail.com (G. Timerga), solomonhailemeskel9@gmail.com (S. Hailemeskel)

${ }^{*}$ Corresponding author

\section{To cite this article:}

Genanew Timerga, Solomon Hailemeskel. Trend Analysis on Maternal Health Care Services Utilization in Amhara Region Referral Hospitals, Ethiopia. International Journal of Nutrition and Food Sciences. Vol. 7, No. 3, 2018, pp. 81-89. doi: 10.11648/j.jpnfs.20180703.11

Received: March 1, 2018; Accepted: March 19, 2018; Published: April 19, 2018

\begin{abstract}
According to World Health Organization (WHO) repot complications arising during pregnancy death accounts 580,000 women of reproductive age each year, and a high proportion of these deaths contributed in sub-Saharan Africa. Impediments to the effective delivery care, ANC and PNC include geographical, financial and cultural barriers. The objectives of this study were to assess the current status of maternal health care services, compared to previous data factors that influence the utilization of these services, and to investigate trend analysis of improvement of utilization of maternal health care services in Amhara region, Ethiopia. Institution based cross sectional study design was conducted in Amhara region referral hospitals from January 2016 to December 2016. Maternal health care service providers in the respective health facilities collected primary and secondary data using structured and semi structured questionnaire. Odds Ratios, Bivariate and Multivariate logistic regression were used to identify predictor variables associated with the dependent variables. A total of 415 primary data and different samples in different year for secondary data were completed and making utilization of Antenatal Care (ANC), Delivery Care (DC) and Postnatal Care (PNC) services in 2000 to 2016 was found to be the children birth order of 1 mothers (primipara) $(21.8 \%, 18.2 \%, 15.5 \%$ and $65.8 \%),(18.4 \%, 18.4 \%, 15.5 \%$ and $50.1 \%)$ and $(31.7 \%, 33.4 \%, 14.4 \%$ and $54.9 \%$ ) with respective years. Women residing in urban areas were 1.5, 1.7, 1.2 and 1.5 times more likely than women in rural areas to receive ANC from a health professional in respective years. Almost all predicted response CI out of covering 1 implies that there was an effect of the factor under consideration. Birth order (gravidity), residence, mothers' education and wealth index in explaining the utilization of maternal health care services confirmed both bivariate and multivariate analyses significant effect in every year.
\end{abstract}

Keywords: Trend Analysis, Multivariate, Factors, CI, MHCS

\section{Introduction}

According to World Health Organization (WHO) repot complications arising during pregnancy death accounts 580,000 women of reproductive age each year, and a high proportion of these deaths contributed in sub-Saharan Africa. [1]. In sub-Saharan Africa the ratio of maternal mortality is one of the highest in the world, estimating levels of 686 per 100,000 live births [2]. Most maternal deaths occur during labor, delivery or the first 24 hours postpartum, and most intra-partum complications cannot be reliably predicted or prevented, though most can be successfully treated with prompt and appropriate diagnosis and care. Antenatal care (ANC) and Postnatal care (PNC) have the potential to contribute in reducing maternal and child morbidity and mortality. The World Health Organization (WHO) has been strongly advocating improvements of maternal health services as part of its Safe Motherhood Initiative (SMI) [3]. Regular antenatal care has long been viewed as important for identifying a small minority of women who are at increased risk of adverse pregnancy outcomes and for establishing good relations between the women and their health care providers [4].

In developed countries, $97 \%$ of women make at least one antenatal visit; $99 \%$ deliver with a skilled attendant; and $90 \%$ 
make at least one postnatal visit. In developing countries coverage of at least one ANC visit is relatively high at $69 \%$ in Sub-Saharan Africa, compared to $54 \%$ in Asia [5]. According to Demographic and Health Survey (DHS) data from 23 African countries, two-thirds of women in SubSaharan Africa give birth at home [6], but only 13\% of all women receive a postnatal visit within two days [7]. Recent sources have challenged the potential of ANC to reduce maternal mortality. Both quality and coverage are essential to maximize the impact. Impediments to the effective delivery of ANC and PNC include geographical, financial and cultural barriers. An estimated seven out of every ten women who do not give birth in a facility are not currently receiving PNC [8]. Policies and programs have largely overlooked this critical period, hindering efforts to meet the Millennium Development Goals (MDGs) for maternal and child survival [9].

According to an evaluative report of Ethiopia, for poor health outcomes among women and children was the non-use of modern health care services by a sizable proportion of women.

In Ethiopia, improvement in the coverage of antenatal care provided by trained health care professionals $(27$ percent in 2000, 28 percent in 2005 and 34 percent in 2011) has been seen over the last 5 years and regarding postnatal care only five percent of mothers received postnatal care within the critical first two days after delivery which indicates that postnatal care is very low in Ethiopia. There have been identified several factors that have important influence on the utilization of maternal health care services in Ethiopia. Most of the factors identified were associated with the demographic and socio-cultural characteristics of women. A study conducted on identifying factors affecting the utilization of maternal health care services among women during their third trimester of pregnancy and within 12 months post-delivery preceding using a community-based cross sectional study which was conducted from October to December 2004 in Ayssaita and Dubti towns in Afar Regional state confirms this statement [10].

Therefore, the purpose of this study was to assess the current status of maternal health care services, compared to previous and current data influence on the utilization of the services, to find factors of underutilization of maternal health care services and to compare the utilization of rural and urban area of maternal health care services among the previous EDHS and the current data in the region.

This study shows the trend of the result of 14 years' corresponding development document analysis of the results and therefore, aims to fill this gap. The current study presents an analysis of the effect of demographic and socio-economic variables on maternal health care utilization. The data used in this study were obtained from the Ethiopian Demographic and Health Survey conducted from 2000 to 2014 and primary data from referral hospitals in the region. It is hoped that the result of the study was help to identify the trend analysis main demographic and socioeconomic factors affecting maternal health care utilization in Ethiopia.

\section{Methods}

\subsection{Study Design}

A cross-sectional study design was conducted in five governmental referral hospitals in Amhara region. In the Region, there are two teaching, three referrals, two zonal, ten district, six general private hospitals and seven hospitals that are under construction to provide services for more than 20 million people. The USAID estimated a population growth rate of 3\% per year and a doubling time of 25 years. This study was conducted in Debre Birhan Referral Hospital, Dessie Referral Hospital, Gondar Referral Hospital, Bahir Dar (Felegehiwot) Referral Hospital and Debre Markos Referral Hospital, in Amhara region, Ethiopia from January 2016 to December 2016.

\subsection{Sample Size and Sampling Technique}

\subsubsection{Target Population}

The target population for this study was those households that served in the referral hospital currently. The sample size required to our study was calculated using the following single population proportion formula

$$
\mathrm{n}=\frac{\mathrm{Z}(\alpha / 2) 2 \mathrm{p}(1-\mathrm{P})}{\mathrm{D}^{2}}
$$

$\mathrm{P}=$ Proportion of MHC service (0.42), Z $(\alpha / 2)^{2}=$ Confidence interval (1.96), D = Margin of error (0.05), $\mathrm{n}=$ 375 , with $10 \%$ non-response rate, $n=413$. The data for this study was taken from the 2000 to 2011 Ethiopian Demographic and Health Survey and primary data were collected in 2016, which was the first of its kind to be undertaken in the region. The study collected information from a regional representative sample of primary and secondary data on women age between 15-49 years. In this study, the responses were analyzed from the total Sample women aged from age 15-49 years; who have at least one under five children at the time of data collection. A number of specific questions were raised and asked of women about their most recent pregnancy and live birth in the five years preceding the survey. We asked the study participants about:

1) Antenatal care (ANC): if a pregnant women were checked and followed by a trained health care professional, that is, doctor, nurse, or midwife, at least once during the time of pregnancy;

2) Health care Professional assisted delivery care (DC): If a laboring mother were attended by a trained health care professional during her delivery; and

3) Postnatal care (PNC): For those mothers who delivered outside a health facility, whether they received a medical checkup from a health professional within 42 days after delivery.

The 2014 EDHS sample was selected using a stratified, two-stage cluster design; enumeration areas (EAs) were the sampling units for the first stage. Households comprised the second stage of sampling. Complete listings of households 
were carried out in each of the 415 sample who were selected for primary data.

\subsubsection{Study Variables}

Dependent variable: utilization of maternal health care

$$
\begin{gathered}
\text { ANC }=\left\{\begin{array}{r}
0 \text { if a mother did not utilize antenatal care } \\
1 \text { if a mother utilized antenatal care (atlist one ANC follow up during pregnancy ) }
\end{array}\right. \\
\mathrm{DC}=\left\{\begin{array}{r}
0 \text { if a mother did not utilize delivery care (Health Institution) } \\
1 \text { if a mother utilized delivery care (at Health Institution by trained health care provider) }
\end{array}\right. \\
\mathrm{PNC}=\left\{\begin{array}{r}
0 \text { if a mother did not utilize postnatal care } \\
1 \text { if a mother utilized postnatal care (atlist one PNC after delivery upto } 42 \text { days) }
\end{array}\right.
\end{gathered}
$$

Independent variable: socio demographic characteristics, availability of maternal health service and other related variables

\subsection{Data Analysis}

In this study, descriptive statistics, odd ratio and both bivariate and multivariate logistic regression analyses were done for the three maternal health care variables. Bivariate statistics analysis was used to observe a significant association between each of the three dependent variables and the social, economic, demographic factors. For the multivariate analysis, the response category was merged to have a dichotomous variable on the basis of whether or not the women had received maternal health care. Since the interest was in identifying women at risk because they did not receive care, the outcome variables were coded as 1 if the women received antenatal care and as 0 if they did not receive antenatal care. The same coding procedure was applied for delivery and postnatal care. This study considers only those women who had at least one live birth in the five years preceding the survey and data. If women had more than one live birth in the past five years, only care received for the most recent live birth is considered. Lastly, we use multivariate analysis for compression and trend analysis of the data which were obtained from 2000 to 2016 years.

Confidence intervals (CIs) are presented for the odds ratios instead of $p$-values since the CI contains more information than p-values. A CI covering 1 implies that there is no effect of the factor under consideration. Otherwise, there is an effect of that variable. A narrow CI implies a large sample size, while a large CI implies a small sample size.

The model was run for the region as a whole and separately for urban and rural areas since factors influencing use of maternal health services were expected to be different between urban and rural areas. Parity in this study is categorized as 1, 2-4 and 5+ and was based on the fact that studies in Ethiopia [11] and elsewhere have shown that the risk of maternal morbidity, mortality and other pregnancyrelated complications are significantly higher among women with five or more children.

\subsection{Ethical Consideration}

This proposal was approved by the research review committee of Debre Berhan University; College of Medicine and Health Sciences. Permission to conduct the study was obtained from the Hospitals. When documents were reviewed, codes were used and anonymity was assured

\section{Results}

Table 1 below shows that examination of differentials and determinants of the most background variables are related with antenatal care, delivery care and postnatal care in live birth in the five years preceding. Utilization of ANC services is found to be the children birth order 1 of mothers $(21.8 \%$, $18.2 \%, 15.5 \%$ and $65.8 \%$ ) children birth order $2-4$ of mothers $(32.5 \%, 41.5 \%, 42.6 \%$ and $24.1 \%)$ and children birth order $5+$ of mothers $(45.7 \%, 40.6 \%, 41.9 \%$ and $10.1 \%)$ with respective years. It was also observed that utilization for delivery care services was $(18.4 \%, 18.4 \%, 15.5 \%$ and $50.1 \%)$, for children birth order 1 of mothers, $(41.5 \%, 41.5 \%$, $42.6 \%$ and $43.4 \%$ ) for children birth order $2-4$ of mothers and $(40.1 \%, 40.1 \%, 41.9 \%$ and $6.7 \%)$ for children birth order $5+$ of mothers with respective years. The same way for postnatal care services of children birth order 1 of mothers $(31.7 \%$, $33.4 \%, 14.4 \%$ and $54.9 \%$ ) children birth order $2-4$ of mothers $(44.8 \%, 33.2 \%, 43.0 \%$ and $41.0 \%)$ and children birth order $5+$ of mothers $(23.5 \%, 33.4 \%, 42.6 \%$ and $4.1 \%)$ with respective years. The proportion of mothers using ANC, delivery care and PNC for birth 1 in the past 5 years relatively increases $(50.8 \%, 73.3 \%, 72.7 \%$ and $27.5 \%)$, $(72.7 \%, 72.7 \%, 73.3 \%$ and $34.7 \%)$ and $(35.4 \%, 64.6 \%$, $64.6 \%$ and $70.8 \%$ ) respectively with respective years. Similarly, for birth $2+$ of ANC, DC and PNC in the past 5 years fluctuate results in different years $(49.2 \%, 26.7 \%$, $27.3 \%$ and $72.7 \%),(27.3 \%, 27.3 \%, 26.7 \%$ and $65.3 \%)$ and

\begin{tabular}{|c|c|c|c|c|c|c|c|c|c|c|c|c|c|}
\hline \multicolumn{14}{|c|}{ Maternal healthcare with respective year } \\
\hline \multicolumn{2}{|c|}{ Background characteristics } & \multicolumn{4}{|c|}{$\begin{array}{l}\text { Percentage of Antenatal Care } \\
\text { (ANC) with respective year }\end{array}$} & \multicolumn{4}{|c|}{$\begin{array}{l}\text { Percentage of Delivery Care } \\
\text { with respective year }\end{array}$} & \multicolumn{4}{|c|}{$\begin{array}{l}\text { Percentage of Postnatal Care } \\
\text { (PNC) with respective year }\end{array}$} \\
\hline Explanatory variable & Categories & 2000 & 2005 & 2011 & 2016 & 2000 & 2005 & 2011 & 2016 & 2000 & 2005 & 2011 & 2016 \\
\hline \multirow{2}{*}{ Mother age at birth } & $15-19$ & 10.8 & 19.4 & 11.3 & 54.9 & 11.3 & 11.3 & 11.3 & 25.3 & 11.3 & 19.7 & 10.8 & 23.4 \\
\hline & $20-34$ & 69.5 & 69.3 & 69.3 & 41.0 & 69.3 & 69.3 & 69.3 & 60.0 & 69.3 & 69.5 & 69.5 & 72.0 \\
\hline
\end{tabular}
$(64.6 \%, 35.4 \%, 35.4 \%$ and $70.8 \%)$ respectively.

Table 1. Percentage of Maternal Healthcare Services in Amhara region referral hospitals with respective year Amhara Region, Ethiopia, 2017. 


\begin{tabular}{|c|c|c|c|c|c|c|c|c|c|c|c|c|c|}
\hline \multicolumn{14}{|c|}{ Maternal healthcare with respective year } \\
\hline \multicolumn{2}{|l|}{ Background characteristics } & \multicolumn{4}{|c|}{$\begin{array}{l}\text { Percentage of Antenatal Care } \\
\text { (ANC) with respective year }\end{array}$} & \multicolumn{4}{|c|}{$\begin{array}{l}\text { Percentage of Delivery Care } \\
\text { with respective year }\end{array}$} & \multicolumn{4}{|c|}{$\begin{array}{l}\text { Percentage of Postnatal Care } \\
\text { (PNC) with respective year }\end{array}$} \\
\hline Explanatory variable & Categories & 2000 & 2005 & 2011 & 2016 & 2000 & 2005 & 2011 & 2016 & 2000 & 2005 & 2011 & 2016 \\
\hline \multirow[b]{3}{*}{ Women's educational status } & $35-49$ & 19.7 & 11.3 & 19.4 & 4.1 & 19.4 & 19.4 & 19.4 & 14.7 & 19.4 & 10.8 & 19.7 & 4.6 \\
\hline & No education & 58.1 & 50.0 & 74.6 & 88.9 & 58.1 & 58.1 & 74.6 & 35.2 & 58.2 & 58.2 & 75.3 & 27.5 \\
\hline & $\begin{array}{l}\text { Primary and above } \\
\text { educ. }\end{array}$ & 41.9 & 50.0 & 25.4 & 11.1 & 41.9 & 41.9 & 25.4 & 64.8 & 41.8 & 41.8 & 24.7 & 72.5 \\
\hline \multirow[b]{2}{*}{$\begin{array}{l}\text { Educational status of } \\
\text { husband }\end{array}$} & No education & 17.5 & 41.9 & 41.9 & 80.7 & 41.9 & 41.9 & 41.9 & 52.0 & 17.5 & 41.8 & 41.8 & 34.2 \\
\hline & $\begin{array}{l}\text { Primary and above } \\
\text { educ. }\end{array}$ & 82.5 & 58.1 & 58.1 & 19.3 & 58.1 & 58.1 & 58.1 & 48.0 & 82.5 & 58.2 & 58.2 & 65.8 \\
\hline \multirow{3}{*}{ Employment status } & Employed & 28.6 & 17.5 & 28.6 & 22.9 & 82.5 & 82.5 & 28.6 & 65.8 & 28.6 & 17.4 & 71.4 & 3.6 \\
\hline & Non-employed & 71.4 & 82.5 & 71.4 & 77.1 & 17.5 & 17.5 & 71.4 & 34.2 & 71.4 & 82.6 & 28.6 & 96.4 \\
\hline & 1 (primipara) & 21.8 & 18.2 & 15.5 & 65.8 & 18.4 & 18.4 & 15.5 & 50.1 & 31.7 & 33.4 & 14.4 & 54.9 \\
\hline \multirow{2}{*}{ Children Birth order (parity) } & 2-4 (multipara) & 32.5 & 41.2 & 42.6 & 24.1 & 41.5 & 41.5 & 42.6 & 43.4 & 44.8 & 33.2 & 43.0 & 41.0 \\
\hline & $\begin{array}{l}5+\text { (grand } \\
\text { multipara) }\end{array}$ & 45.7 & 40.6 & 41.9 & 10.1 & 40.1 & 40.1 & 41.9 & 6.7 & 23.5 & 33.4 & 42.6 & 4.1 \\
\hline \multirow{3}{*}{ Wealth index } & Poor & 19.0 & 21.5 & 23.6 & 2.9 & 15.3 & 15.3 & 23.6 & 8.4 & 56.6 & 21.6 & 23.2 & 4.6 \\
\hline & Middle & 57.1 & 63.0 & 19.5 & 11.1 & 21.5 & 21.5 & 19.5 & 50.6 & 31.7 & 62.9 & 19.5 & 23.4 \\
\hline & Rich & 23.9 & 15.5 & 56.9 & 86.0 & 63.2 & 63.2 & 56.9 & 41.0 & 11.7 & 15.5 & 57.3 & 72.0 \\
\hline \multirow{3}{*}{ Household head } & Male & 75.3 & 71.4 & 82.5 & 96.4 & 27.8 & 27.8 & 82.5 & 88.9 & 64.6 & 70.8 & 82.5 & 72.5 \\
\hline & Female & 24.7 & 28.6 & 17.5 & 3.6 & 72.2 & 72.2 & 17.5 & 11.1 & 35.4 & 29.2 & 17.5 & 27.5 \\
\hline & Orthodox & 41.1 & 44.2 & 31.4 & 85.3 & 44.2 & 44.2 & 31.4 & 62.2 & 41.6 & 44.2 & 31.2 & 85.3 \\
\hline \multirow{3}{*}{ Religion } & Protestant & 15.0 & 21.0 & 21.0 & 8.9 & 21.0 & 21.0 & 21.0 & 12.0 & 13.9 & 21.1 & 21.1 & 9.4 \\
\hline & Muslim & 40.5 & 31.4 & 44.2 & 3.9 & 31.4 & 31.4 & 44.2 & 20.2 & 41.1 & 31.2 & 44.2 & 3.9 \\
\hline & Others & 3.4 & 3.4 & 3.4 & 1.4 & 3.4 & 3.4 & 3.4 & 5.5 & 3.4 & 3.5 & 3.5 & 1.4 \\
\hline \multirow{3}{*}{ Birth in the past 5 years } & 1 & 50.8 & 73.3 & 72.7 & 27.5 & 72.7 & 72.7 & 73.3 & 34.7 & 35.4 & 64.6 & 64.6 & 70.8 \\
\hline & $2+$ & 49.2 & 26.7 & 27.3 & 72.5 & 27.3 & 27.3 & 26.7 & 65.3 & 64.6 & 35.4 & 35.4 & 29.2 \\
\hline & Low & 59.4 & 59.4 & 16.0 & 72.0 & 35.9 & 35.9 & 32.6 & 16.6 & 59.1 & 61.9 & 54.4 & 86.0 \\
\hline \multirow[t]{2}{*}{ Household Decision } & Medium & 20.3 & 20.2 & 47.9 & 23.4 & 27.6 & 27.6 & 33.6 & 30.4 & 20.0 & 21.2 & 20.2 & 11.1 \\
\hline & High & 20.3 & 20.4 & 36.1 & 4.6 & 36.5 & 36.5 & 33.8 & 53.0 & 20.9 & 16.9 & 25.4 & 2.9 \\
\hline \multirow{2}{*}{ Residence } & Rural & 54.1 & 60.2 & 47.1 & 34.2 & 50.0 & 50.0 & 47.1 & 34.9 & 50.4 & 48.8 & 46.4 & 11.1 \\
\hline & Urban & 45.9 & 39.8 & 52.9 & 65.8 & 50.0 & 50.0 & 52.9 & 65.1 & 49.6 & 51.2 & 53.6 & 88.9 \\
\hline
\end{tabular}

As compared to religion, orthodox mothers use the services (ANC $41.1 \%, 44.2 \%, 31.4 \%$ and $85.3 \%$ ), (delivery care $15.0 \%, 44.2 \%, 31.4 \%$ and $62.2 \%$ ) and (PNC $41.6 \%$, $44.2 \%, 31.2 \%$ and $85.3 \%$ ) respective years. For protestant mothers, they less to use ANC $(15.0 \%, 21.0 \%, 21.0 \%$ and $8.9 \%)$, delivery care $(41.1 \%, 21.0 \%, 21.0 \%$ and $12.0 \%)$ and PNC $(13.9 \%, 21.1 \%, 21.1 \%$ and $9.4 \%)$ with respective year services. On the other hand, Muslim mothers tend to occupy an intermediate position in using ANC $(40.5 \%, 31.4 \%$, $44.2 \%$ and $3.9 \%)$, delivery care $(40.5 \%, 34.1 \%, 44.2 \%$ and
$20.2 \%)$ and PNC (41.1\%, 31.2\%, 44.2\% and 3.9\%) with respective year and other religion followers mother take the least position in utilization of ANC, delivery care and PNC services with respective year (Table 1). All other variables interpreted in a similar manner.

With regard to residence of the response, urban mothers were more likely to use ANC, delivery care and PNC services than rural mothers with respective years, as show in figure 1 below.

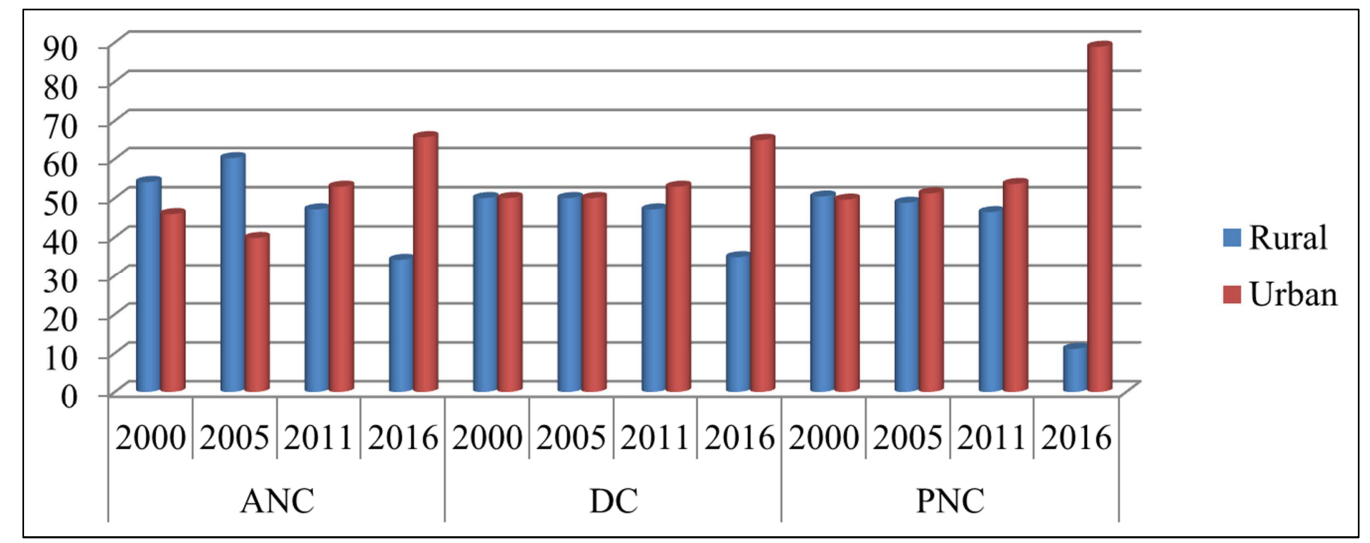

Figure 1. Residence response on trend analysis on maternal health care services utilization in Amhara region referral hospitals, Ethiopia, 2017. 


\subsection{Bivariate Analysis}

Bivariate statistical analysis addresses the marginal effect of a predictor variable on the response without taking into account other predictors. It also shows the association between the outcome variable and other predictor variables, obtained by cross tabulation of the response variables, maternal healthcare (i.e. ANC, Delivery care and PNC) usage to the other predictor variables independently. Bivariate analysis was done for 11 variables and except employment status and religion in2016 of ANC and delivery care and 2011 religion, all others variables are statistically significant at $5 \%$ (since, $\mathrm{p}<0.05)$ significance level for all the three maternal health care's.

Table 2 displayed the results of the likelihood of attending a PNC for those mothers who had already attended both ANC and DC previously is about 0.39 , a randomly selected mother has a probability of $24.4 \%$ of utilizing all the MHCs.
Table 2. Conditional probability of mothers' attendance of all MHCs in Amhara region referral Hospitals, Amhara Region, Ethiopia, 2017.

\begin{tabular}{lllll}
\hline PNC & & & & \\
\hline ANC & DC & Yes & No & Total \\
\hline \multirow{2}{*}{ Yes } & Health Institution & 623 & 968 & 1591 \\
& Home & 534 & 2648 & 3182 \\
\multirow{2}{*}{ No } & Health Institution & 131 & 206 & 337 \\
& Home & 280 & 764 & 1044 \\
\hline
\end{tabular}

$\mathrm{P}(\mathrm{PNC}=\mathrm{Using} / \mathrm{DC}=\mathrm{Using}, \mathrm{ANC}=\mathrm{Using})=0.39 ; \mathrm{P}(\mathrm{ANC}=\mathrm{Using}, \mathrm{DC}=$ Using, $\mathrm{PNC}=$ Using) $=0.10$

\subsection{Multivariate Analysis}

\section{i. Antenatal Care}

Results of the multivariate analysis for the region as a whole reinforce the importance of place of residence; children birth order, employment status, Wealth index and women's education as the most important determinants of antenatal care utilization (Table 3 ). Women residing in urban areas are $1.5,1.7,1.2$ and 1.5 times more likely, respectively, than women in rural areas to receive antenatal care from a health professional in respective years.

Table 3. Adjusted odds ratios and 95 percent confidence intervals for receiving Antenatal care in Amhara region referral Hospitals, Amhara Region, Ethiopia, 2017

\begin{tabular}{|c|c|c|c|c|c|}
\hline \multicolumn{2}{|l|}{ Background characteristics } & \multicolumn{4}{|c|}{ Confidence Intervals of Antenatal Care (ANC) with respective year } \\
\hline Explanatory variable & Categories & 2000 & 2005 & 2011 & 2016 \\
\hline \multirow{3}{*}{ Mother age at birth } & $15-19$ & 1 & 1 & 1 & 1 \\
\hline & $20-34$ & $1.9[1.5-3.1]$ & $0.9[0.4-1.3]$ & $2.2[1.9-5.1]$ & $2.3[0.7-3.5]$ \\
\hline & $35-49$ & $3.2[2.9-4.9]$ & $2.1[2.0-2.8]$ & $3.3[2.1-5.9]$ & $4.1[3.6-5.8]$ \\
\hline \multirow{2}{*}{ Women's educational status } & No education & 1 & 1 & 1 & 1 \\
\hline & Primary and above educ. & $1.6[1.3-2.1]$ & $2.4[2.1-3.2]$ & $1.2[1.0-2.3]$ & $1.8[1.6-2.5]$ \\
\hline $\begin{array}{l}\text { Educational status of } \\
\text { husband }\end{array}$ & No education & 1 & 1 & 1 & 1 \\
\hline \multirow{2}{*}{ Employment status } & employed & 1 & 1 & 1 & 1 \\
\hline & Non-employed & $1.1[0.7-1.9]$ & $1.2[0.5-3.1]$ & $1.1[0.6-3.1]$ & $5.4[4.7-6.8]$ \\
\hline \multirow{3}{*}{ Children Birth order } & 1 (primipara) & 1 & 1 & 1 & 1 \\
\hline & 2-4 (multipara) & $0.9[0.6-1.4]$ & $1.7[0.7-2.4]$ & $1.3[0.8-3.2]$ & $2.2[0.9-3.1]$ \\
\hline & $5+($ grand multipara $)$ & $1.0[0.7-2.9]$ & $2.2[1.5-4.4]$ & $1.7[0.6-3.8]$ & $2.3[1.0-4.9]$ \\
\hline \multirow[b]{2}{*}{ Wealth index } & Poor & 1 & 1 & 1 & 1 \\
\hline & Middle & $3.5[2.3-4.3]$ & $1.2[0.8-1.7]$ & $1.5[1.3-1.3]$ & $3.3[2.1-4.2]$ \\
\hline Household head & Female & $0.6[0.2-1.5]$ & $0.6[0.2-2.5]$ & $1.7[0.8-2.1]$ & $1.5[1.2-2.5]$ \\
\hline \multirow{4}{*}{ Religion } & Orthodox & 1 & 1 & 1 & 1 \\
\hline & Protestant & $1.6[1.3-2.5]$ & $0.8[0.4-1.5]$ & $2.1[1.9-2.4]$ & $1.3[0.8-2.0]$ \\
\hline & Muslim & $1.3[1.0-1.6]$ & $1.0[0.6-1.7]$ & $5.0[4.6-6.7]$ & $11.0[9.1-13.0]$ \\
\hline & Others & $0.8[0.3-1.2]$ & $1.8[0.9-2.2]$ & $2.8[2.3-4.2]$ & $3.1[2.5-6.1]$ \\
\hline \multirow{2}{*}{ Birth in the past 5 years } & 1 & 1 & 1 & 1 & 1 \\
\hline & $2+$ & $0.8[0.6-1.5]$ & $0.3[0.1-1.1]$ & $0.2[0.0-1.1]$ & $0.7[0.5-3.1]$ \\
\hline \multirow{3}{*}{ Household Decision } & Low & 1 & 1 & 1 & 1 \\
\hline & Medium & $2.1[0.9-2.4]$ & $1.3[0.9-2.9]$ & $1.1[0.9-1.9]$ & $1.2[1.0-2.8]$ \\
\hline & High & $0.3[0.1-0.9]$ & $2.7[2.1-4.3]$ & $3.3[2.9-3.9]$ & $3.7[3.1-5.3]$ \\
\hline \multirow{2}{*}{ Residence } & Rural & 1 & 1 & 1 & 1 \\
\hline & Urban & $1.5[1.1-1.9]$ & $1.7[1.3-2.8]$ & $2.2[1.9-3.8]$ & $1.5[1.3-2.8]$ \\
\hline
\end{tabular}

\section{ii. Delivery Care}

Table 4 presents multivariate results of DC for the overall sample show that place of residence, women's education, employment status, and birth in the past 5 years are independent predictors of utilization of delivery care services in the region. Women residing in urban area are about 4.1 times more likely to receive assistance during delivery than rural women in 2016, while women from different years are about 1.2 times and above more likely to receive assistance during delivery than rural women. The odds ratio of delivery care utilization by mothers from middle and wealth index compared to those mothers from rich wealth index are 1.5 
(1.5, 95\% CI: $1.3-3.4)$ in 2011 and 3.3 (3.3, 95\% CI: $2.1-4.2)$ in 2016 and $1.4(1.4,95 \% \mathrm{CI}: 1.0-2.1)$ in 2011 and $6.2(6.2$, 95\% CI: 5.1-7.6) in 2016, respectively. Utilization of professional assistance at delivery in urban region is estimated to have increased over the last five years by 32 percent per year between 2005 and 2016, assuming a linear trend, the trends are shown in Figure 2.

Table 4. Adjusted odds ratios and 95 percent confidence intervals for receiving Delivery care in Amhara region referral Hospitals, Amhara Region, Ethiopia, 2017

\begin{tabular}{|c|c|c|c|c|c|}
\hline \multirow{2}{*}{$\begin{array}{l}\text { Background characteristics } \\
\text { Explanatory variable }\end{array}$} & \multirow[b]{2}{*}{ Categories } & \multicolumn{4}{|c|}{ Confidence Intervals of Delivery Care (DC) with respective year } \\
\hline & & 2000 & 2005 & 2011 & 2016 \\
\hline \multirow{3}{*}{ Mother age at birth } & $15-19$ & 1 & 1 & 1 & 1 \\
\hline & $20-34$ & $1.0[0.5-2.1]$ & $0.9[0.3-1.4]$ & $2.0[1.6-3.1]$ & $3.2[2.5-4.6]$ \\
\hline & $35-49$ & $8.0[6.9-11.1]$ & $2.1[2.0-2.8]$ & $2.1[1.8-4.3]$ & $7.3[6.1-9.9]$ \\
\hline \multirow{2}{*}{ Women's educational status } & No education & 1 & 1 & 1 & 1 \\
\hline & Primary and above educ. & $1.2[1.0-2.1]$ & $2.0[1.3-3.1]$ & $2.7[2.3-4.4]$ & $1.6[1.2-2.4]$ \\
\hline \multirow{2}{*}{ Educational status of husband } & No education & 1 & 1 & 1 & 1 \\
\hline & Primary and above educ. & $0.3[0.1-1.2]$ & $0.8[0.5-1.6]$ & $1.4[1.1-2.5]$ & $2.1[2.0-3.3]$ \\
\hline \multirow{2}{*}{ Employment status } & employed & 1 & 1 & 1 & 1 \\
\hline & Non-employed & $1.2[0.5-1.1]$ & $1.1[0.7-1.6]$ & $2.1[1.6-3.1]$ & $3.4[2.7-4.8]$ \\
\hline \multirow{3}{*}{ Children Birth order } & 1 (primipara) & 1 & 1 & 1 & 1 \\
\hline & 2-4 (multipara) & $0.9[0.6-2.1]$ & $0.3[0.1-1.4]$ & $1.0[0.4-2.2]$ & $0.9[0.6-1.5]$ \\
\hline & $5+$ (grand multipara) & $0.3[0.1-1.9]$ & $0.2[0.6-2.8]$ & $0.7[0.5-2.4]$ & $2.0[1.6-2.8]$ \\
\hline \multirow{3}{*}{ Wealth index } & Poor & 1 & 1 & 1 & 1 \\
\hline & Middle & $0.4[0.3-1.5]$ & $2.1[1.8-3.8]$ & $1.3[1.1-2.2]$ & $3.5[2.3-4.3]$ \\
\hline & Rich & $1.2[0.6-2.1]$ & $1.0[0.6-2.1]$ & $1.4[1.1-2.0]$ & $2.2[1.8-3.6]$ \\
\hline \multirow{2}{*}{ Household head } & Male & 1 & 1 & 1 & 1 \\
\hline & Female & $0.6[0.2-1.8]$ & $0.5[0.2-1.5]$ & $1.2[1.0-2.1]$ & $1.6[1.2-2.5]$ \\
\hline \multirow{4}{*}{ Religion } & Orthodox & 1 & 1 & 1 & 1 \\
\hline & Protestant & $0.8[0.4-1.5]$ & $1.3[0.8-2.0]$ & $1.4[1.1-2.4]$ & $2.1[1.8-2.5]$ \\
\hline & Muslim & $0.7[0.5-1.6]$ & $1.0[0.6-1.7]$ & $3.0[2.1-4.0]$ & $5.0[4.6-6.7]$ \\
\hline & Others & $0.5[0.3-1.2]$ & $1.8[1.3-2.4]$ & $2.8[2.5-4.4]$ & $3.1[2.7-6.3]$ \\
\hline \multirow{2}{*}{ Birth in the past 5 years } & 1 & 1 & 1 & 1 & 1 \\
\hline & $2+$ & $2.8[1.6-3.9]$ & $1.7[1.3-2.4]$ & $2.4[2.1-3.1]$ & $1.3[1.1-4.1]$ \\
\hline \multirow{3}{*}{ Household Decision } & Low & 1 & 1 & 1 & 1 \\
\hline & Medium & $1.1[0.9-1.9]$ & $1.3[0.9-2.9]$ & $1.5[0.9-2.1]$ & $1.3[1.0-2.5]$ \\
\hline & High & $0.3[0.1-0.9]$ & $0.7[0.1-2.3]$ & $3.3[2.9-3.9]$ & $3.7[3.1-5.3]$ \\
\hline \multirow{2}{*}{ Residence } & Rural & 1 & 1 & 1 & 1 \\
\hline & Urban & $2.3[1.9-3.7]$ & $1.7[1.2-2.5]$ & $1.2[1.1-2.1]$ & $4.1[3.8-6.8]$ \\
\hline
\end{tabular}

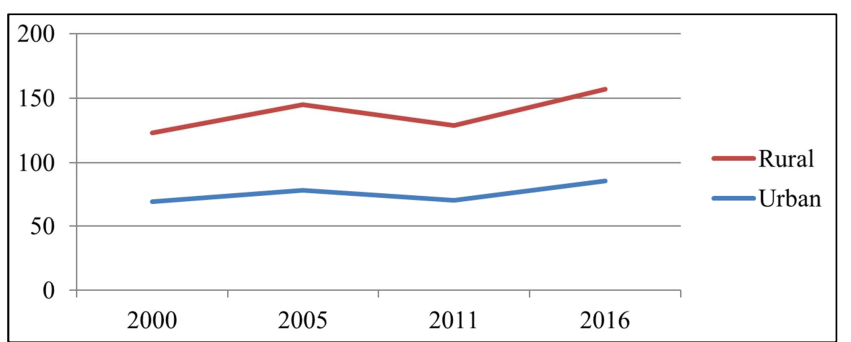

Figure 2. Delivery Care by residence on maternal health care services utilization in Amhara region referral hospitals, Ethiopia, 2017. iii. Postnatal Care

Multivariate analysis of the influence of variables on the utilization of postnatal care by mothers who delivered outside a health facility showed that women education, children birth order, employment status, sex of household head and birth in the past five years are factors that do not significantly influence its use in the region with respective years (Table 5). Women residing in urban are more likely to use PNC services than their rural counterparts in respective years. Due to the small number of postnatal care users, no separate analysis by residence is presented. Observed trends can be seen in Figure 2 above.

Table 5. Adjusted odds ratios and 95 percent confidence intervals for receiving postnatal care in Amhara region referral Hospitals, Amhara Region, Ethiopia, 2017.

\begin{tabular}{|c|c|c|c|c|c|}
\hline \multirow{2}{*}{$\begin{array}{l}\text { Background characteristics } \\
\text { Explanatory variable }\end{array}$} & \multirow[b]{2}{*}{ Categories } & \multicolumn{4}{|c|}{ Confidence Intervals of Postnatal Care (PNC) with respective year } \\
\hline & & 2000 & 2005 & 2011 & 2016 \\
\hline \multirow{3}{*}{ Mother age at birth } & $15-19$ & 1 & 1 & 1 & 1 \\
\hline & $20-34$ & $1.2[0.7-2.6]$ & $0.8[0.3-1.5]$ & $1.1[0.8-3.3]$ & $2.0[1.6-3.1]$ \\
\hline & $35-49$ & $8.0[6.9-11.1]$ & $1.1[0.8-2.7]$ & $3.2[2.5-4.6]$ & $7.3[6.2-9.7]$ \\
\hline \multirow{2}{*}{ Women's educational status } & No education & 1 & 1 & 1 & 1 \\
\hline & Primary and above educ. & $1.2[0.4-2.0]$ & $1.0[0.7-2.8]$ & $0.6[0.2-1.6]$ & $1.4[0.9-2.5]$ \\
\hline \multirow{2}{*}{ Educational status of husband } & No education & 1 & 1 & 1 & 1 \\
\hline & Primary and above educ. & $0.5[0.1-1.8]$ & $0.8[0.5-1.7]$ & $2.1[0.8-3.1]$ & $1.3[1.0-2.4]$ \\
\hline \multirow{2}{*}{ Employment status } & employed & 1 & 1 & 1 & 1 \\
\hline & Non-employed & $0.9[0.6-1.8]$ & $1.1[0.8-1.9]$ & $2.1[1.0-2.9]$ & $1.4[0.7-2.8]$ \\
\hline Children Birth order & 1 (primipara) & 1 & 1 & 1 & 1 \\
\hline
\end{tabular}




\begin{tabular}{|c|c|c|c|c|c|}
\hline \multicolumn{2}{|c|}{ Background characteristics } & \multicolumn{4}{|c|}{ Confidence Intervals of Postnatal Care (PNC) with respective year } \\
\hline Explanatory variable & Categories & 2000 & 2005 & 2011 & 2016 \\
\hline \multirow{5}{*}{ Wealth index } & 2-4 (multipara) & $0.2[0.6-2.4]$ & $0.9[0.5-2.1]$ & $1.3[0.7-2.1]$ & $1.2[0.7-1.9]$ \\
\hline & $5+$ (grand multipara) & $0.8[0.1-1.9]$ & $0.5[0.1-1.4]$ & $0.7[0.5-2.4]$ & $1.7[1.0-2.8]$ \\
\hline & Poor & 1 & 1 & 1 & 1 \\
\hline & Middle & $0.3[0.1-1.2]$ & $1.1[0.8-1.8]$ & $0.4[0.3-1.5]$ & $3.5[2.3-4.3]$ \\
\hline & Rich & $1.2[0.6-2.5]$ & $1.3[0.6-2.7]$ & $1.4[0.9-2.0]$ & $2.2[1.8-3.6]$ \\
\hline \multirow{3}{*}{ Household head } & Male & 1 & 1 & 1 & 1 \\
\hline & Female & $1.6[0.7-2.4]$ & $0.6[0.3-1.9]$ & $1.6[1.2-2.8]$ & $1.2[1.0-2.4]$ \\
\hline & Orthodox & 1 & 1 & 1 & 1 \\
\hline \multirow{3}{*}{ Religion } & Protestant & $1.3[0.9-2.3]$ & $1.8[0.7-2.5]$ & $1.3[1.0-2.7]$ & $2.1[1.8-2.5]$ \\
\hline & Muslim & $0.7[0.4-1.9]$ & $0.7[0.5-2.2]$ & $1.0[0.6-2.3]$ & $5.0[4.6-6.7]$ \\
\hline & Others & $1.0[0.6-1.8]$ & $1.1[0.3-2.4]$ & $1.8[0.5-2.4]$ & $3.1[2.7-6.3]$ \\
\hline \multirow{2}{*}{ Birth in the past 5 years } & 1 & 1 & 1 & 1 & 1 \\
\hline & $2+$ & $1.3[0.7-2.4]$ & $1.4[0.8-2.4]$ & $1.7[0.5-2.1]$ & $0.9[0.3-2.2]$ \\
\hline \multirow{3}{*}{ Household Decision } & Low & 1 & 1 & 1 & 1 \\
\hline & Medium & $1.2[0.6-2.3]$ & $1.3[0.7-2.6]$ & $1.2[0.8-2.4]$ & $1.9[1.0-2.9]$ \\
\hline & High & $0.7[0.1-2.3]$ & $0.5[0.2-1.6]$ & $1.3[0.9-2.8]$ & $3.7[3.1-5.3]$ \\
\hline \multirow{2}{*}{ Residence } & Rural & 1 & 1 & 1 & 1 \\
\hline & Urban & $1.8[1.3-2.7]$ & $1.9[1.5-4.8]$ & $0.8[0.3-2.0]$ & $1.7[0.3-1.9]$ \\
\hline
\end{tabular}

\section{Discussion}

In this study, the factors: sex of household head in 2011 to 2016, mother age at birth, mother education, husband education in 2016, birth order, religion, wealth index, residence are significantly associated with improved utilization of maternal healthcare services.

Strong association has been found between household wealth and the use of maternal health services which is also supported by other studies [12] and [13]. This can be explained by the fact that women should be able to cover the costs needed in order to access healthcare services. Even in areas where maternal healthcare services are provided for free, women still have to pay for transportation and additional costs. As a result, only those women who can afford to pay for such costs are able to visit health facilities.

The result of predicted probabilities for use of ANC, delivery care and PNC in this study showed that women in the highest wealth index group despite differences in place of residence and educational level were found to have higher level of use of ANC, delivery care and PNC in respective years. But wealth index is a big problem in urban and rural in each year. Based on our result, wealth index variations are increasing from year to year. This depicts that household wealth is a very strong determinant of health service utilization. The Ethiopian Society of Population Studies [13] also found that women in households with the lowest wealth index are less likely to seek maternal healthcare services than women in households with middle wealth quintile and the probability of seeking healthcare services is higher among women with the highest wealth index. This finding is also consistent with a study done in Philippines [14]. Birth order of the child shows significant association with the use of ANC, delivery care and PNC services in 2016. Use of these maternal health services was shown to decrease with increase in birth order.

Age of the mother at birth was found to be significantly related to ANC, delivery care and PNC in the total sample.
The result of this study also shows that mothers giving birth at older ages are more likely to use maternal healthcare services than adolescents and young mothers. Generally, mothers giving birth at older ages in urban area are better to use ANC, DC and PNC when compared to rural area. A study done on determinants of the use of maternal child health service in rural Ghana found that older mothers are more likely to use maternal health care services than younger mothers [15]. The result of this study is also consistent with a study done in rural Bangladesh [16].

Residence of mother was found to be specifically associated with the utilization of ANC, delivery care and PNC services in this study. The result shows that mothers' residence is positively associated with utilization of $\mathrm{ANC}$, delivery care and PNC services from health professionals with respective years. But now days, there is a significant change in rural area. This implies mothers who reside in urban use maternal healthcare services more likely than those who are living in rural. Experiences and roles as economic providers might empower mothers through increased control over income which, in turn, may increase their power in decision-making about healthcare and their ability to access and pay for the services that they need.

The results of this study also showed that mothers married to husbands with primary or higher educational level tend to use the service more than those mothers who had uneducated husband. Education was found to have an important impact on the use of maternal health services suggests that improving educational opportunity for women may have a large impact on improving utilization of such services.

The results from both the bivariate and multivariate analyses confirmed the importance of birth order, residence, mothers' education and wealth index in explaining the utilization of health care services in each year. Women education retains a net effect on maternal health service use, independent of other women's background characteristics, households' socioeconomic status and access to health care services in the region and also mother education in rural area 
is very important to the utilization of maternal health care services. The strong influence of mothers' education on the utilization of health care services is consistent with findings from other studies. The results from [11], [17], [18] and [19] results are in line with our findings. Moreover, these findings are also similar to those documented in many settings throughout Africa and other developing countries.

\section{Conclusion}

The findings of these study revealed that maternity health care services are found to be higher among urban women as well as women with at least secondary education compared to the rural area in the region, as clearly shown by the major maternity care indicators: antenatal care, delivery care and postnatal care. The study verifies that young (15-19) and older (35-49) mothers are less likely to seek antenatal care than mothers in the reference category (20-34) in respective years. The probability of seeking health care services is higher among women at the household with the highest wealth index in respective years in the region. The results from both the bivariate and multivariate analyses confirmed the importance of birth order, residence, mothers' education and wealth index in explaining the utilization of health care services in each year. Education has an important impact through delivering information using radio, television and community health extension workers targeting those mothers who do not attend maternal health services. To improve the child morbidity and mortality, it is better to address the high rate of defaulter, low rate of weight gain and long length of stay in the program. Considering the economic situation of the population is a long term national and regional objective and goes beyond the responsibility of the Ministry of Health. Accessibility of health facilities gives high attention in rural area.

\section{Limitations}

The study only tries to see maternal health service utilization only on antenatal care; delivery care and postnatal care hence, other variables which could be included under maternal health care utilization were not seen.

\section{Acknowledgements}

The authors are very grateful to Debre Berhan University for financial support. We also appreciate the support and cooperation that we got from Amhara region hospitals during data collection.

\section{Authors' Contributions}

GT raised the research questions and developed the design of the study, performed the data entry and analysis, and participated in the manuscript write up. SH involved in the preparation of designing the study, involved during the analysis, interpretation and developed the manuscript and wrote the sections meticulously. All of these authors provided critical comments and approved the final version of the manuscript.

\section{Disclosure}

The authors declare that there is no conflict of interest in this work.

\section{References}

[1] WHO (2010). Trends in Maternal Mortality: 1990 to 2008, estimates developed by WHO, UNICEF, UNFPA and The World Bank.

[2] World Bank. 1994a. Better health in Africa: Experience and lessons learned. Washington, D. C. World Bank. 1994b. World development report: Infrastructure for development. New York, New.

[3] World Health Organization (WHO). 1998. Improved access to maternal health services. WHOYork: Oxford University Press.

[4] Mrisho M, Obrist B, Armstrong- Schellenber J, Haws RA, Mushi AK, Mshinda H, Tanner M and Schellenberg D (2009): The use of antenatal and postnatal care: perspectives and experiences of women and health care providers in rural southern Tanzania. BMC Pregnancy and Childbirth 368:1377-1386.

[5] UNICF\FMOH. Safe motherhood action agenda: priorities for the next decade, 1987-1998. United Nations Children"s Fund. (UNICEF) (2006). State of the World"es children. United Nations Children's Fund, New York.

[6] Central Statistical Authority (CSA) Ethiopia and ORC Macro. (2006). Ethiopia Demographic and Health Survey (EDHS) 2005. Addis Ababa, Ethiopia and Calverton, Maryland, USA.

[7] Lawn, J. and Kerber, K. (2006). Opportunity for Africa Newborns: Practical data, policy and programmatic support for newborn care in Africa. Eds. PMNCH, Cape Town.

[8] Yoder, R. (1989) Are people willing and able to pay for health services? Social Scientific Medicine; 29 (1): 35-44.

[9] United Nations (UN) (2008), The Millennium development Goals Report 2008, New York.

[10] Melkamu, F. (2005). Assessment of Factors affecting utilization of maternal health care service in Ayssaita and dubit towns, Afar Regional state, north East Ethiopia.

[11] Yared, M. and Asnaketch M. (2002) „Utilization of Maternal Healthcare Services in Ethiopia"e. Calverton, Maryland, USA: ORC Macro.

[12] Babalola, S. and Fatusi, A. (2009) 'Determinants of use of maternal health services in Nigeria - looking beyond individual and household factors'. BMC Pregnancy and Childbirth 2009, 9:43.

[13] Ethiopian Society of Population Studies (2008) 'Maternal Healthcare Seeking Behavior in Ethiopia: Findings from EDHS 2005', Addis Ababa.

[14] Wong EX, Popkm BM, Guilkey DK, Akin JS (1987). Accessibility, Quality of Care and Prenatal Care Use in the Philippines. Social Science and Medicine, 24: 927 - 944. 
[15] Addai, I. (2000). Determinants of use of maternal-child health services in rural Ghana. Journal of Biosocial Science 32 (1):1-15.

[16] Chakraborty, N., Islam M. A., Chowdhury, R. I., Bari, W., and Akhter, H. H. (2003) "Determinants of the use of maternal health services in rural Bangladesh”. Health PromotInt 2003; 18:327-37.

[17] Habtamu Z. (2008). Trend and Determinants of utilization of maternal health care service in Amhara regional state; evidence from EDHS 2000 and 2005. A Thesis submitted to the school of graduate studies of Addis Ababa University.
[18] Meseret K. 2010. Statistical analysis of factors affecting usage of maternal health care services in four regions of Ethiopia.

[19] Kassu M. 2012. Determinant factors affecting utilization of maternal health care services in rural Ethiopia. 